\title{
Diffusion of Information and Communication Technologies in communication of agricultural information among agricultural researchers and extension workers in Kenya
}

\author{
Joseph Kiplang'at ${ }^{\prime}$ \\ Moi University, School of Information Sciences \\ Department of Library, Records Management and Information Studies, \\ P.O. Box 3900,Eldoret, Kenya \\ jkngetich@yahoo.co.uk
}

and

Dennis N. Ocholla ${ }^{2}$

University of Zululand Department of Library and Information Science

P.O. Private Bag x I00I, Kwadlangezwa 3886, South Africa.

docholla@pan.uzulu.ac.za

Received : $15^{\text {th }}$ May 2005

Accepted: $5^{\text {th }}$ October 2005

\begin{abstract}
The paper reports on the findings of a study that investigated the diffusion of Information and Communication Technologies (ICTs) in communication of agricultural information among agricultural researchers and extension workers in Kenya. The study focused on the public agricultural sector and covered the Kenya Agricultural Research Institute (KARI) and the Ministry of Agriculture and Rural Development (MoARD). A survey research method, comprising a self-completed questionnaire and a structured interview schedule was utilized to gather data from the respondents who comprised of 159 agricultural researchers, 138 extension workers and 59 key informants. This was supplemented by observation and document review.

It was found out that KARI and MOARD had adopted a wide variety of ICT tools and services in an effort to facilitate information sharing and exchange among agricultural researchers, extension workers, farmers and other actors involved in research and extension. These ranged from modern ICTs based on digital information and traditional ICTs based largely on analogue information waves. The ICT models adopted addressed the different kinds of information needs and communication problems encountered by agricultural researchers and extension workers. However, it was observed that despite the efforts to expand and modernize ICTs in the agricultural sector, its growth had been hampered by a number of constraints and challenges which require the intervention and interaction of all the stakeholders in the agricultural and ICT sector and also involvement of the government.
\end{abstract}

\section{Background and problem statement}

This paper reports on the findings of a study that investigated the diffusion of Information and Communication Technologies (ICTs) in communication of agricultural information among agricultural researchers and extension workers in Kenya (Kiplang'at 2004). Information and Communication Technology is defined variably. For example, Heeks (1999:2) defines ICTs as electronic means of capturing, processing, storing, and communicating information and categorises ICTs to include: digital information held as Is and 0 s and comprises computer hardware, software and networks and intermediate technology based largely on analogue information waves such as radio, television, and telephone.

Kenya's economy is heavily dependent on the agricultural sector that also provides the basis for the development of other sectors (Kenya, Republic of, National Development Plan 2002:23). Its direct contribution to Gross Domestic Product (GDP) is $25 \%$ and indirectly contributes a further $27 \%$ through linkages with agro-based and associated industries (KARI 2002:I). The sector employs about $75 \%$ of the total labour force, generates $60 \%$ of export earnings, and provides $75 \%$ of industrial raw materials and $45 \%$ of Government revenue (KARI 2002:I). About $80 \%$ of Kenya's population live in the rural areas and are engaged in agricultural activities. The majority of this population are smallholder farmers who account for $75 \%$ of the total agricultural output in the country (KARI 2002:I). In addition to its role in the national economy, the agricultural sector is also key to the livelihood of many Kenyans in food security and nutritional balance (KARI 2000:6). The sector's output, however, is hampered by several factors. One of the major factors adduced for the low agricultural productivity in the country is the lack of adequate information support to all the stakeholders in

I. Joseph Kiplang'at, PhD, is Senior Lecturer in the Department of Library, Records Management and Information Studies, Moi University, Kenya

2. Dennis N. Ocholla is Professor and Head of the Department of Library and Information Science, University of Zululand, South Africa 
agricultural production. Factors that may have contributed to inadequate information support include the lack of appropriate agricultural information systems and services, the lack of appreciation of the role of timely and relevant information, and ineffective linkages among agricultural researchers, extension workers, farmers and other actors in research and extension (Kenya, Republic of, Ministry of Agriculture 1997:2).

In an effort to rectify this anomaly, the Kenya Government through the Ministry of Agriculture, commissioned a study (Kenya, Republic of, Ministry of Agriculture 1998:26) to look into the deficits of the existing "information landscape" in the agricultural sector and suggest strategies for improving the situation The study found out that the inadequate information provision was partly because there were no systematic procedures for information collection, analysis, storage and dissemination, and partly because each development agency collects its own data with little or no coordination with the rest (Kenya, Republic of, Ministry of Agriculture 1998:2). Information exchange and dissemination, therefore, remain serious constraints on the agricultural production potential in the country.

The rapid development and applications of the Internet and other forms of ICTs in the Kenyan agricultural sector have presented a whole new dimension in the transfer and access of agricultural information, which previously was difficult and expensive to obtain. It is expected that these technologies will improve communication and provision of agricultural information among agricultural researchers, extension workers and other actors involved in research and extension. Through the application of ICTs, free flow of information would be enhanced and this could facilitate the adoption of agricultural technologies ultimately improving agricultural productivity in the country. It should, however, be noted that for ICTs to improve the provision of agricultural information other inputs and/or conditions such as skill development, policy and regulatory framework, and conducive infrastructure are necessary.

This study was conceived with the aim of establishing the nature, types and distribution of ICTs in the agricultural sector in Kenya and assessing the extent to which they were used in the communication of agricultural information among agricultural researchers and extension workers. The broad aim was achieved by mapping and auditing of ICTs in the agricultural sector in Kenya, to establish their nature, types and distribution and motivation behind the adoption; exploring government and institutional ICT policies and their effect on adoption and diffusion of ICTs in the agricultural sector in Kenya; examining the information literacy programmes available in the institutions surveyed and how such programmes contribute towards use of ICTs among agricultural researchers and extension workers; investigating the extent to which information needs of agricultural researchers and extension workers are met through ICTs; assessing the demand and use of ICTs by agricultural researchers and extension workers in their knowledge acquisition and knowledge dissemination process; investigating the impact of ICTs use on communication of agricultural information among agricultural researchers and extension workers in the agricultural sector; establishing knowledge gaps, drawbacks, and limitations that hinder effective use of ICTs by agricultural researchers and extension workers; assessing the funding, maintenance and sustainability of ICTs in the agricultural sector in Kenya; establishing the constraints and challenges encountered in diffusion of ICTs in the agricultural sector in Kenya and suggesting and recommending measures to be taken into account in improving diffusion and use of ICTs in the agricultural sector in Kenya.

\section{Theoretical Considerations}

The study was informed largely by the Diffusion of Innovation (Dol) theory commonly referred to as Rogers' theory that has been discussed in more details in a separate paper in this issue (Minishi-Majanja and Kiplang'at 2005). The Dol theory is essentially a social process in which subjectively perceived information about a new idea is communicated. Rogers and Scott (1999:4) have defined diffusion as the process by which an innovation is communicated through certain channels over time among members of a social system. The theory rests on the premise that a new idea, practice or object has perceivable channels, time and mode of being adopted by individuals or organisations. The theory has potential application to information technology, ideas, artefacts, and techniques (Clarke 1999:1). It has been used as the theoretical basis for a number of information systems projects (Rogers and Scott 1999:8, Surry 1997:8, Larsen 1997, Larsen 1998). The theory has also been widely applied to investigate diffusion of agricultural innovations (Rogers and Scott 1999:4, Rogers 1995, Sunding \& Zilberman 2000, Minishi - Majanja and Kiplang'at 2004 and 2005). Thus the theory's application to information technology and agriculture made it the most appropriate theoretical framework for this study. The strength of the theory is that adopters and non-adopters of an innovation may be studied to identify the factors that influence their adoption behaviour (Lewis 1997:7, Ojiambo 1989:38). Some of these influences include: the nature of the innovation, the communication channels, the characteristics of social group, institutions or organizations (Lewis 1997:7, Ojiambo 1989:38, Minishi-Majanja and Kiplang'at 2005).

There are always reasons for introducing an innovation in an organization. As rightly pointed out by Rogers (1995) the innovation process begins with agenda setting where one or more individuals in an organization identify an important problem and then seek an innovation as a means of coping with the problem. Rogers (1995) further observes that the 
problem usually emanates from a performance gap which is the discrepancy between how the organization is performing in comparison to its potential. He is of the view that the discrepancy is identified by members of the organization and is a strong impetus that compels them to search for an innovation to solve the identified problem.

For example, the agenda setting in the Ministry of Agriculture and Rural Development (MoARD) was prompted by the problem of low agricultural production in Kenya. The main factor that contributed to low production was identified as lack of adequate information support to all stakeholders in agricultural research and extension. In mid July 1996 the MoARD commissioned a study to critically evaluate the existing information landscape, including information flow among actors involved in research and extension (Kenya, Republic of, MoARD, 1997:1). The study revealed information deficits due to ineffective agricultural information system. It recommended the establishment of the Agricultural Sector Information Network (ASIN) to acquire, process, and disseminate information to the staff of the ministry and other stakeholders (Kenya, Republic of, MoARD 1997:26). The system was to be established at the ministry headquarters and networked directly via communication links to the branches at the provincial and district agricultural offices. It was further recommended that ICTs should be adopted to facilitate communication of agricultural information among all actors involved in research and extension. Similarly, the Kenya Agricultural Research Institute (KARI) found itself ill-prepared to contribute to and benefit from cutting-edge information on technological innovations, and was therefore lagging behind (KARI 2002:46). In particular, KARI scientists were not receiving adequate support in terms of accessing reference materials, including scientific journals and databases relevant to their programmes. An Information and Technology Unit was, therefore, established to coordinate adoption and use of ICTs in the institution (KARI 2002:46). The policy makers at MOARD and KARI therefore identified ICTs (innovation) as a solution for improving communication of agricultural information. The innovation in this study was, therefore, ICTs.

In this paper diffusion is viewed as a process by which ICTs (innovation) are communicated through certain channels (e.g. information literacy programmes) over time among agricultural researchers and extension workers (members) at KARI and MOARD (social systems). The attributes determining the rate of adoption of ICTs (innovation) among agricultural researchers and extension workers were also examined. Thus the four key elements in Rogers's theory fitted well in the study.

\section{Research Methodology}

Both qualitative and quantitative research designs have been used. A survey research method, comprising self-completed questionnaire and structured interview schedule was utilized to gather data from the respondents. This was supplemented by observation and document review. Questionnaire was used to solicit information from agricultural researchers and extension workers, while face-to-face interview was used to obtain information from the key informants of the study. Due to the diverse and enormous nature of the agricultural sector in Kenya, the study covered only the public agricultural sector. The private sector did not form part of the study as its contribution to research and extension in the country is minimal. Although the government is in the process of privatizing agricultural research and extension, these services are still largely the responsibility of the government through the Kenya Agricultural Research Institute (KARI) and the Ministry of Agriculture and Rural Development. The study, therefore, covered all the 21 main KARI research centres strategically spread throughout the eight provinces in country to cater for different agro-ecological zones and socioeconomic systems. This ensured that the centres exhibited a broad ecological diversity and different levels of infrastructural development in the country. The research centres also depicted different levels of infrastructural development and provided useful information on the level of ICT distribution. At the time of conducting the study, KARI had a total of 382 agricultural researchers distributed in the 21 research centres. Stratified and random sampling were used to sample $191(50 \%)$ agricultural researchers. In addition, KARI headquarters was included for purposes of interviewing the top management staff and coordinators of research programmes. We also covered the Ministry of Agriculture and Rural Development (MOARD). The MoARD have provincial and district agricultural offices distributed across the country. It was not possible to cover all the extension workers who are spread across the country. We therefore used purposive sampling to select one province that has a representation of dense as well as sparse population, depicted different agro-ecological zones as well as various levels of infrastructure development. The province that met the stipulated criteria was the Rift Valley Province. The province has a total of 18 districts. The cluster sampling technique was used to cluster the districts within the province into two categories as follows:

- Districts with high and medium agricultural potential areas, dense population and relatively good infrastructure and

- Districts in the arid and semi-arid areas, sparse population and relatively poor infrastructure.

We then purposively selected one district from each of the two clusters/categories. The districts selected were Uasin Gishu district which represented districts in the high and medium potential areas and Baringo district representing districts in the arid and semi-arid land. The two districts also depicted different levels of communication infrastructure, 
and were either densely or sparsely populated. This disparity provided the basis for comparing diffusion of ICTs in the two districts. The MoARD headquarters and the Agricultural Information Centre (AIC) also formed part of the study.

The extension workers were therefore drawn from the two districts. Out of 212 extension workers at Uasin Gishu district, 106 (50\%) were selected for the study. While in Baringo district out of 96 extension workers, 48 (50\%) were selected for the study. The extension workers were distributed in the divisions within the two districts and each division had an agricultural office to coordinate the extension activities .

A fifty percent sample size was drawn from the study population. This size was essential to minimize cost and safe time given the difficulty of reaching all the respondents. Mugenda and Mugenda (1999:43) argue that a 50\% sample is large enough and can be used to represent the target population. Assumingly, such population would be large enough to justify sampling.

Three types of interview schedules were used to solicit information from three categories of key informants who comprised of 24 policy makers, 27 librarians/information professionals, and 8 Information Technology (IT) personnel drawn from the institutions surveyed including the Agricultural Information Centre (AIC).

The completed 297 questionnaires and recorded interviews from 59 informants formed the basis of data analysis and interpretations. A coding scheme was developed for closed-ended questions and input into the Statistical Package for Social Sciences (SPSS). Data was then analysed using descriptive statistics where frequencies, cross tabulations, percentages, and means were calculated, and data presented accordingly. Relationships among variables were compared and interpretations made.

Open-ended responses and recorded interviews were analysed using content analysis methodology. Mugenda and Mugenda (1999: 174) assert that content analysis involves logical groupings of the data with similar messages. Open-ended questions were, therefore, scanned to determine which words or phrases were frequently used by the respondents. An index of all the responses was constructed. The data was then recorded according to the frequency by which the phrases was cited.

\section{Results and discusions}

A total of 356 respondents comprising of 159 (44.6\%) agricultural researchers, 138 (38.8\%) extension workers and $59(16.6 \%)$ key informants participated in this study. The completed questionnaires were reviewed to determine their usability. Two questionnaires were discarded because they were incomplete. A total of 295 questionnaires comprising of 159 agricultural researchers and 136 extension workers and 59 recorded interviews were usable. This brought the total number of respondents to 354 .

\subsection{Characteristics of respondents}

We assume that the male domination in agricultural research and extension professions had reduced as a result of the Kenya Government taking measures to ensure gender equity at all levels of education and development. For example, when comparing some of the results from a study by Ojiambo(1989) and that done by Kiplang'at (2004) it was observed that male domination in agricultural research had declined from $73.8 \%$ in 1989 to $64 \%$ in the year 2003 , while that of the extension workers had decreased from $78.1 \%$ to $71 \%$. It was noted that most of the agricultural researchers (120; $75.5 \%)$ were between the ages of thirty and forty-nine years. A significant number $(91 ; 57.4 \%)$ of extension workers were between thirty and thirty nine years of age.

The agricultural researchers were highly qualified for their jobs as 126(79.1\%) had masters and Ph.D. degrees in specialized fields in agriculture. The figure $(79.1 \%)$ represents $28.3 \%$ more than the educational qualifications of agricultural researchers $(50.8 \%)$ reported by Ojiambo (1989). Similarly, the education level of extension workers had improved considerably with the majority $(103 ; 65 \%)$ having bachelors' degree, as opposed to diploma and certificate qualifications (eg I 30; 82.1\%) reported in earlier studies (Ojiambo 1989, Kaniki 1995). It was further noted that while half of agricultural researchers $(52.7 \%)$ obtained their qualifications abroad, the majority of extension workers $(91.1 \%)$ were trained locally in Kenya.

The nature of work of the agricultural researchers included agronomists, plant and animal breeders, pathologists, entomologists, soil scientists, horticulturists, social-economists, Geographical Information System (GIS) experts amongst others. Extension workers were deployed to district and divisional agricultural offices as subject matter specialists in livestock production, poultry, crop production, soil science, horticulture, bee keeping, farm management, farm mechanization, and home economics, amongst others.

\subsection{Information needs of agricultural researchers and extension workers}

The findings indicate that both agricultural researchers and extension workers had a critical need for information that was specific to the nature of their work. This included information on agronomy, seed technology, soil science, horticulture, plant pathology, bee keeping, dairy cattle and goats, poultry, agricultural marketing, crop protection, amongst others. 
They also expressed need for information on agricultural policies and meteorology. The agricultural policies are important to researchers and extension workers as they provide guidelines on issues affecting research and extension work. For example, the Agricultural Input Policy ensures that adequate and quality inputs are made available to farmers and that, to a greater extent, they are used at the right time and in correct quantities. On the other hand, meteorological information is quite crucial to agricultural researchers and extension workers. Agricultural researchers need information on the climate and weather patterns to assist in planning for their research, while extension workers need to advise farmers on when to plant. Besides, this information helps in forecasting production of food crops and livestock. It is the responsibility of agricultural researchers and extension workers to synthesize, interpret, and disseminate this meteorological information in a timely and effective manner to the farmers.

\subsection{Nature, types and distribution of ICTs}

A wide variety of ICTs tools and services exist among the institutions surveyed. These included the ICTs based largely on analogue information waves that ranged from radios, tape recorders, television, video cameras, VCR, television, fixed line telephone, mobile phones, fax (both analogue and digital), among others. ICTs based on digital information included computers, Internet, email, scanners, digital cameras amongst others. Tables Ia and Ib below indicate the distribution of fax, Internet and email services, and number of computers at each of the KARI research centres and the Ministry of Agriculture and Rural Development.

Table I a Availability of Fax, Internet and email services, and number of computers at each of the KARI research centres

\begin{tabular}{|c|c|c|c|c|c|c|}
\hline & KARI RESEARCH CENTRES & Fax lines & Internet & ISP Used & Email & No. Of Computers \\
\hline 1 & KARI HQs & 5 & Connected & Kenyaweb & connected & 91 \\
\hline 2 & Kitale & I & Connected & Multitecweb & Connected & 22 \\
\hline 3 & Kibos & । & None & - & None & 4 \\
\hline 4 & Molo & None & None & - & Connected & 7 \\
\hline 5 & Njoro & 1 & Connected & Africa Online & Connected & 25 \\
\hline 6 & Tigoni & I & None & - & Connected & 9 \\
\hline 7 & Muguga South & 1 & Connected & Kenyaweb & Connected & 23 \\
\hline 8 & National Agricultural Research Laboratory & I & Connected & Kenyaweb & Connected & 46 \\
\hline 9 & Thika & 1 & Connected & NairobiNet & Connected & 11 \\
\hline 10 & Mwea Tabere & I & Connected & Africa Online & Connected & 20 \\
\hline 11 & Katumani & I & Connected & Africa Online & Connected & 22 \\
\hline 12 & Muguga North & I & Connected & Kenyaweb & Connected & 19 \\
\hline 13 & Naivasha & 1 & Connected & Africa Online & Connected & 17 \\
\hline 14 & Marsabit & I & None & - & Connected & 3 \\
\hline 15 & Kiboko & I & None & - & Connected & 10 \\
\hline 16 & Kakamega & 1 & Connected & Africa Online & Connected & 13 \\
\hline 17 & Kisii & I & Connected & NairobiNet & Connected & 12 \\
\hline 18 & Embu & 1 & Connected & Salpha Net & Connected & 35 \\
\hline 19 & Garissa & 1 & None & - & Connected & 3 \\
\hline 20 & Mtwapa & I & Connected & Africa Online & Connected & 10 \\
\hline 21 & Perkerra & I & None & - & Connected & 8 \\
\hline 22 & Lanet & I & Connected & Wananchi online & Connected & 12 \\
\hline
\end{tabular}

Table Ib Availability of fax, Internet and email services, and number of computers at institutions surveyed in the ministry of agriculture and rural development

\begin{tabular}{lccccc}
\hline Ministry of Agriculture and Rural Development & Fax lines & Internet & ISP Used & Email & No. Of Computers \\
\hline Ministry of agriculture HQ & I5 & Connected & African online & connected & 700 \\
Agricultural Information Centre & I & None & - & Connected & 15 \\
Uasin Gishu district agricultural offices & I & Connected & Multitecweb & Connected & 5 \\
Baringo district agricultural office & I & None & - & None & 2 \\
\hline
\end{tabular}

Table Ia indicates that out of 2 I KARI research centres, 15 had Internet and email services, 5 had email services only, while only I centre had none of the services. Most of these services were funded through donor projects as the policy of KARI is to include component of Internet and email services in all projects. This enhanced accessibility of Internet and 
email services among agricultural researchers. All the centres had telephone services, while fax services were available in all except Molo research centre. The number of computers varied from one centre to the other with KARI headquarters having the highest number (9l) of computers. The computers, however, were found to be inadequate in most of the research centres. Besides, most of the computers were Pentium I and 2 which are slow, especially when connected to the Internet. Several initiatives had been made to enhance the use of mobile phones by agricultural researchers. At the KARI headquarters 4 mobile phone lines had been installed in the main PABX telephone system. Selected key researchers at Kakamega and Kitale research centres had also been given official mobile phones and were getting a monthly allowance for airtime credit.

Table Ib indicates that the Ministry of Agriculture headquarters and Uasin Gishu district agricultural office had Internet and email services, while the Agricultural Information Centre (AIC) had email services only. Baringo district agricultural office had none of the services and arrangement had been made for extension workers to access the services from the neighbouring district development office. The number of computers varied from one agricultural office to the other with the ministry of agriculture headquarters having the highest number of 700 computers. It was observed that all the district agricultural offices had computers, but none was available at the divisional agricultural offices. It was noted that whenever the frontline extension officers needed to use computers they travelled long distances to their respective district agricultural offices.

Most of the institutions surveyed had dial up Internet connection apart from KARI headquarters, which had both dialup and dedicated line connections. The institutions had a range of proprietary and open-source software. These include Standard Microsoft Office suite, statistical packages such as SPSS, lotus, CD-ISIS, WordPerfect, Dbase, Oracle, Linux, Page-maker, and clippers. Operating systems included MS DOS, MS Windows, UNIX, Novell, and Macintosh. A number of GIS software were also available.

The libraries and information centres in the institutions surveyed had variety of electronic information sources including CD-ROM databases, electronic journals and in-house databases. The CD-ROM databases provided information in bibliographic, full-text and multi-media format. An example of a popular full-text CD-ROM database is The Essential Electronic Agricultural Library (TEEAL) which has a collection from 141 agricultural journals stored on 172 discs and holding images of 750,000 full text pages with illustrations and diagrams. This database is popular and provides a wide range of agricultural information relevant to the needs of agricultural researchers. Among other CD-ROM titles available at KARI libraries and the Ministry of agriculture library at headquarters include AGRIS, AGRICOLA, CABI, Crop Protection Compendium, and Rural and Tropag. These databases were not accessible to most of the extension workers unless they travelled to the nearest KARI research centre or to the Ministry of Agriculture library at the headquarters.

It was observed that the Kenya Web, a leading Internet Service Provider (ISP) in Kenya was hosting KARI Website. A number of KARI research centres located within the vicinity of Nairobi were also utilising the services of this ISP to connect to the Internet. It was further observed that all the KARI centres including the Ministry of Agriculture headquarters, provincial and the district agricultural offices used commercial ISPs chosen depending on the proximity, cost, and quality of service.

KARI headquarters had a fully operational Local Area Network (LAN) with email address that enabled the staff to communicate via the network and access the Internet and email services. Other research centres that had installed LAN were Mtwapa, Perkerra, Kisii, Katumani, Thika, Kitale and the National Agricultural Research Laboratory (NARL). The networking software used was Novell NetWare and lines were connected via routers. Unshielded twisted pair was used in cabling and networking the offices, while coaxial cable was used to network temporary buildings such as green houses. Fibre optic was used for underground cabling. KARI is also benefiting from the Kenya Education Network (KENET) initiative funded by USAID. The KENET initiative uses satellite and Very Small Aperture Technology (VSAT) to network all research and educational institutions in the country. The Ministry of Agriculture was in the process of networking all the offices at the headquarters at the cost of Kenya Shillings 14 million (USD 175,000). Cabling of offices had already been done using switchers, routers and fibre optic. The provincial and district agricultural offices were yet to be networked.

The Agricultural Information Centre (AIC) with a mandate of repackaging agricultural information had a modern radio studio equipped with professional sound recording for both field and studio recording. It also had modern recording equipment and editing suites amongst a variety of other video production facilities. A range of audio-visual facilities also existed in most institutions surveyed.

The motivation behind the adoption and use of ICTs among the institutions surveyed was to improve the efficiency and effectiveness of delivering agricultural information among all actors involved in agriculture. It became clear that whereas the institutions were generating useful information and technologies that were beneficial to diverse groups within and outside the institutions, there was no organised mechanism of packaging, storing and disseminating this 
information. In particular KARI realised that its scientists were not receiving adequate support in terms of accessing reference materials, including scientific journals and databases relevant to their programmes.

\subsection{Accessibility and use of ICT tools and services by agricultural researchers and extension workers}

The respondents were asked to indicate the level of accessibility of ICT tools and services in their respective centres and agricultural offices. The aim was to establish the extent to which the available ICT were accessible to agricultural researchers and extension workers. The respondents were provided with a list of ICTs tools and services and asked to rate them accordingly on the likert scale of I (not accessible) through 4 (very accessible). The mean score was calculated to indicate the perceived accessibility of ICT tools and services to each category of respondents, highest mean score being 4.00 and lowest mean score being 1.00. Table 2 summarizes the responses from agricultural researchers and extension workers respectively.

Table 2 Accessibility of ICT tools and Services to Agricultural Researchers and Extension Workers

\begin{tabular}{lcccc}
\hline & \multicolumn{2}{c}{$\begin{array}{c}\text { Agricultural Researchers } \\
\text { N=I59 }\end{array}$} & \multicolumn{2}{c}{$\begin{array}{c}\text { Extension workers } \\
\text { N= I36 }\end{array}$} \\
\hline ICTs tools and services & Mean Score & Std deviation & Mean Score & Std deviation \\
\hline Computers & 3.55 & 0.63 & 2.07 & 1.17 \\
Telephone & 3.17 & 0.84 & 3.05 & 1.00 \\
Email & 2.86 & 0.95 & 1.63 & 0.99 \\
Fax & 2.83 & 1.03 & 2.05 & 1.08 \\
Mobile Phone & 2.81 & 1.23 & 2.66 & 1.24 \\
Video & 2.47 & 1.21 & 1.81 & 0.94 \\
Television & 2.42 & 1.22 & 2.07 & 0.92 \\
CD-ROM databases & 2.35 & 1.21 & 1.15 & 0.64 \\
Radio & 2.32 & 1.39 & 2.30 & 1.05 \\
Internet & 2.21 & 0.99 & 1.49 & 0.91 \\
Electronic journals & 1.65 & 0.99 & 1.04 & 0.45 \\
GIS & 1.74 & 1.08 & 1.00 & 0.32 \\
Desktop publishing & 1.78 & 1.12 & 1.27 & 0.80 \\
\hline
\end{tabular}

The most accessible ICT tools to agricultural researchers were computers, telephone, email, fax and mobile phones in that order. The television, video, radio, CD-ROM databases and the Internet were fairly accessible and the least accessible were electronic journals, GIS and desktop publishing.

In regard to extension workers, the most accessible ICT tools and services were telephone and to some extent mobile phones. Radio was fairly accessible. However, the Internet, email, CD-ROM databases, electronic journals and GIS were less accessible to extension workers .

The study sought to establish the extent to which information needs of agricultural researchers and extension workers were met through ICTs. The majority of agricultural researchers (II4;7I.7\%) were of the view that the Internet and CD-ROM databases provided information that was relevant to their needs, while most of the extension workers $(97 ; 71.3 \%)$ observed that the information was not useful. This contrast is attributed to the level of skills development and physical access to ICTs by the two categories of respondents. While the majority of agricultural researchers were computer literate and had access to the Internet and CD-ROM databases, most of the extension workers lacked basic computer skills and physical access to ICTs.

It was observed that KARI was a beneficiary of free access to electronic journals courtesy of the International Availability to Scientific Publication (INASP) project through its Programme for the Enhancement of Research Information (PERI). Through this project agricultural researchers were able to access the African Journals Online (AJOL). They were also able to access 600 journals through INASP and Blackwell Synergy project and 5500 full-text journals from the EBSCO Host with seven databases. It was observed that most KARI research centres had made arrangement for agricultural researchers to access the Internet and email services free of charge. The costs were subsidized through the donor projects. At the Uasin Gishu district agricultural office extension workers also accessed Internet and email free of charge but the services were used sparingly because of costs. The institutions were also contemplating charging a minimal fee to sustain the services.

A significant number $(107 ; 73.5 \%)$ of agricultural researchers and a relatively smaller number $(50 ; 36.8 \%)$ of extension workers used the Internet in their research and extension work. A large number of the respondents spent an average of 5 hours per week surfing the Internet. Among the most used Internet service was the email. It was used for 
consultation purposes, for communicating agricultural information, and for research through the CTA Question and Answer Service (QAS). It was mostly the agricultural researchers who used the QAS. In QAS the users completed a questionnaire requesting for information after which it was transmitted electronically to other nodes that may be in a position to provide the information. It was established that the email was a useful tool for collaborative projects among agricultural researchers within ASARECA (Association for Strengthening of Agricultural Research in Eastern and Central Africa) member countries and also at global level. KARI researchers had also benefited from Africa-link project funded by USAID that provide support for dialup Internet and email connections for African researchers.

Among the CD-ROM databases having the most relevant content to agricultural researchers was The Essential Electronic Agricultural Library (TEEAL) as observed earlier. The database covers a wide range of subjects that include: crop production, plant diseases, farm mechanics, tillage and soils, agricultural economics, natural resources, the environment, food science, animal and human nutrition, forestry, genetic resources and breeding and tropical plants. The content corresponded to the needs of agricultural researchers and extension workers. Crop Protection Compendium which is multimedia encyclopaedic CD-ROM database with information of over 1560 pests on 180 crops had relevant content for agricultural researchers and extension workers. The database was available in all KARI research centres and also at the ministry of agriculture library at the headquarters.

KARI had also developed an in-house database called the Kenya Agricultural Research Database (KARD) containing all researches that had been conducted since the establishment of the institute. The database has more that 50,000 records and was distributed offline to all KARI research centres. The database had information on local content and agricultural researchers found it very useful.

Most of the extension workers lacked requisite skills and physical access to the Internet and CD-ROM databases. They relied entirely (100\%) on printed sources of information such as handbooks, pamphlets, newsletters, brochures, leaflets and other extension materials produced by the Agricultural Information Centre (AIC). Informal discussions with them revealed that they also depend on seminars, workshops, and monthly consultative meetings. Similarly, agricultural researchers $(144 ; 90.6 \%)$ also reported that they used printed sources of information to complement the information they obtain via the Internet and CD-ROM databases. The respondents also obtained their information through the radio, television, and newspapers.

Radio and television were used widely by agricultural researchers and extension workers to disseminate agricultural information to the farming community. A variety of programmes had been recorded at the Agricultural Information Centre (AIC) in the national language, Kiswahili, and also in vernacular languages. The programmes contained messages on technological and agricultural development issues and were transmitted by the national radio and TV station (KBC) and also through the private radio and TV stations. Among the popular Kiswahili radio programmes were sikio la mkulima (an ear of the farmer) and tembea na majira (move with the times), while popular TV programmes included agricultural documentaries and Sahiwal cattle. Videos were also widely used to repackage technological messages for extension workers and farmers. They were found to be effective in disseminating agricultural information as a picture is worth a thousand words. Several agricultural video programmes had been produced by the AIC in collaboration with KARI, NGO's and Community Based Organizations (CBOs), Churches and Agro-Chemical industries. The video programmes were quite useful and effective in disseminating agricultural information to farmers.

We observed that mobile phone was used by the respondents to communicate urgent messages and make inquiries based on their day-to-day agricultural activities. The respondents also provided farmers with their mobile numbers to facilitate consultation whenever the farmers were in need of agricultural information. Further observations and interviews revealed that some of the KARI research centres had made arrangements to purchase mobile phones for the selected key officers. These officers were also given monthly allowances for airtime credit. Similarly, the ministry of agriculture was making arrangements to purchase mobile phones for all the district agricultural extension officers and other key officers at the district level. Companies in the private sector are also supporting the use of mobile phones to communicate agricultural information. For example, we noted, the Kenya Agricultural Commodity Exchange (KACE) has partnered with Safaricom mobile subscriber to provide agricultural market information that include, commodity prices, advertisements to buy or sell, and export and import opportunities. All the subscribers of Safaricom can now access this information from their mobile phones by using Short Message Service (SMS) to key in the product name, for example, "Maize Prices On", and dial "4II", thereafter, follow instructions to get price information of the commodity. This is an additional source of information to the respondents and especially extension workers based in the rural areas. The majority of the respondents observed that the SMS mode of communication was becoming a favoured niche medium.

A large number $(129 ; 81.1 \%)$ of agricultural researchers observed that use of ICTs had increased their work productivity and creativity, while $84(6 \mathrm{I} .8 \%)$ of extension workers were either undecided or disagreed. This is attributed to lack of skills and physical access to ICTs. 
Most of agricultural researchers (129; $81.1 \%)$ and over half of extension workers $(74 ; 54.4 \%)$ were of the view that ICTs had changed their way of seeking information from libraries and information centres. Among the reasons given was that ICTs were convenient, effective, and efficient and provide enormous pool of information in one sitting without traveling to libraries and information centres. Furthermore, they noted that ICTs allow faster and efficient sharing and exchange of information among all actors involved in research and extension. They observed that use of ICTS had enhanced production and dissemination of extension materials to suit different target groups ranging from the illiterate to literate farmers.

However, while a large number of agricultural researchers (II3; 7I.7\%) used ICTs to communicate with extension workers, ironically, only $48(35.3 \%)$ of the extension workers used ICTs to communicate with agricultural researchers. One would have expected ICTs to enhance the communication between agricultural researchers and extension workers. Besides, the two subsystems are supposed to work more closely together in transmitting new knowledge of farm technology to farmers and also getting feedback from farmers. Among the major constraint contributing to infrequent communication is that while agricultural researchers had access to the Internet and email services, the majority of extension workers lacked physical access to these ICT tools and services.

4.6 Knowledge gaps, limitations and challenges encountered in diffusion of ICTs in the agricultural sector in Kenya. The lack of computer and Internet skills by the majority of respondents was a major constraint to use of ICTs. Although most of the agricultural researchers had good computer and Internet skills, the majority (140; 88\%) needed more training on use of Internet, electronic journals and CD-ROM databases. A large number (93; 68.4\%) of extension workers had poor skills and over $122(90 \%)$ needed training in all aspects of ICTs. Related to this constraint was the nonavailability of ICTs among the respondents. The most vulnerable group was the extension workers whom over $88(65 \%)$ had no access to computers, Internet, email, CD-ROM databases and electronic journals. The most affected were the frontline extension workers based at the divisional/local agricultural offices. The few extension workers who had acquired some computer skills through self-study lacked the hands-on experience and often relapsed into computer illiteracy. Although the information literacy programmes were better coordinated by KARI than the MOARD, most of the respondents had not benefited much from these programmes.

Associated with the above problems were inadequate funds to acquire and sustain ICT tools and services. The centralized budgeting system at KARI and the Ministry of Agriculture was blamed for contributing towards inadequate funding. More often than not the budgets approved were extremely inadequate. The most affected were the district/ regional agricultural offices that had to contend with the basic provision of services. KARI research centres were relatively better off because of the alternatives sources of funds through donor projects. At the two district agricultural offices ICT budget was usually the most affected and in most cases it was reduced to bare minimum to cater for only telephone services. Despite the constraints the respondents were enthusiastic in keeping pace with the technological advances as portrayed by the extension workers at the Uasin Gishu district agricultural office. They had to forgo their field allowances to subsidize funds set aside for the purchase of computers and training costs. In the end there was surplus money to cater for the cost of connecting to the Internet.

The other problem was the high costs of maintenance which was aggravated by lack of IT personnel at the research centres and district agricultural offices. The few IT personnel employed were all stationed at the headquarters of KARI and the Ministry of Agriculture. Due to inadequate funds the research centres and agricultural offices could not afford to contract private consultants to maintain their ICT facilities. As a result many computers that broke down could not be repaired and were rendered obsolete. Consequently, most of the institutions found it difficult to develop capacity for ICT absorption and utilization without the IT personnel. The problem was partly attributed to failure to attract skilled professionals to the public sector and partly to lack of appreciation of ICTs by policy makers.

Sustainability of ICTs was affected by inadequate funding and lack of planning especially for donor funded projects. Although on paper KARI usually commits itself to sustain the donor funded projects once they end, this was not always fulfilled because of several such projects that had been initially started. Those managing the donor funded projects felt that their institutions often retreat when the projects end leaving no option but to terminate the ICTs services. On the other hand, the policy makers argued that many projects could end at the same time making it difficult to sustain given the limited funds available. They further observed that in some cases the donor funded projects were often initiated without giving them ample time to decide what was good for their institutions. It was observed that these projects had tended to provide initial investment capital rather than maintenance and running costs. As a result the recurrent costs associated with maintenance have remained largely unmet.

The poor infrastructure in the rural areas affected diffusion of ICTs among the respondents. A number of research centres and agricultural offices were unable to connect to the Internet due to low bandwidth and had to contend with 
email services that do not require a high bandwidth. Coupled with this was the fact that most ISPs were in big towns and because of distance there was often poor connectivity to the Internet and email services. Frequent down-time of the Internet and email frustrated the respondents from effectively using the services. It was noted that the problem can be reduced with the expansion of telecommunication services in the rural areas.

Lack of comprehensive national and institutional policy on ICTs was also mentioned as a constraint to diffusion of ICTS in the agricultural sector. In addition, lack of monitoring and evaluation system made it difficult to know the performance, effectiveness, and efficiency of the adopted ICTs and whether they were sustainable in the long run. Many ICTs projects needed to be rejuvenated to meet the changing needs of the respondents.

\section{Conclusions}

We observe that despite the constraints and challenges encountered in the application and use of ICTs in the agricultural sector, a wide range of ICTs had been adopted to facilitate information sharing and exchange among agricultural researchers and extension workers. This ranged from modern ICTs such as the Internet, email, electronic sources to traditional media such as radio, television and video. The variety of ICTs diversified the channels for disseminating agricultural information among agricultural researchers, extension workers, farmers, and also between actors involved in research and extension. Interpreted in light of the diffusion of innovation theory (Rogers 1995), the findings indicate that ICTs that were perceived by the respondents as having relative advantage and were more compatible with their existing values, past experiences and needs were adopted faster. For example, mobile phones had a faster rate of diffusion among the agricultural researchers and extension workers despite the high tariffs.

KARI and the Ministry of Agriculture must however address a number of constraints and challenges which hinder the expansion and modernization of ICTs in the agricultural sector. Among them include the inadequate funding, poor infrastructure, inadequate skills development, lack of comprehensive institutional ICT policy, lack of monitoring and evaluation system, inadequate provision of ICTs tools and services, poor maintenance, and over-reliance of donor funded projects leading to low level of sustainability. To address these issues requires the intervention and interaction of all stakeholders in the agricultural and ICT sector.

It suffices to say that ICTs have even a greater role to play in the context of the changing paradigms in agricultural research and extension, where linear information flows are being replaced by pluralistic information flows and new actors are emerging to form "community information spaces" (Ajit 2003:3) This development can be enhanced by the availability and accessibility of ICTs by agricultural researchers and extension workers.

We recommend the following measures to be addressed at institutional and national level to improve diffusion of ICTs in the agricultural sector.

\section{-Infrastructure}

Although the Kenya Government is expanding and improving ICT systems, the current state of infrastructure is still a major hindrance to the country's full participation in the information society. Substantial demands for basic services remain unmet and the disparity in the distribution of communication facilities between rural and urban areas continues to widen.

\section{Telecommunication infrastructure}

As a matter of urgency the Government should privatize Telkom Kenya Limited and increase participation of the private sector in the provision of fixed public telephone services. The proceeds from the sale of Telkom Kenya could be used to finance modernization, rehabilitation, diversification and expansion of telephone services in the country. Involvement of private companies in providing telephone services would allow for rapid increase of telephone lines, and this it is hoped will reduce unit costs and inject management expertise that will improve efficiency and lower tariffs. This would also improve service penetration levels and tele-density in the rural and urban areas.

The government should also improve the efficiency of Internet backbone popularly known as JamboNet with a hub in Nairobi and extending to all major towns in the country. To enhance access and facilitate points of presence in most parts of the country, JamboNet should be extended to all district headquarters. This would provide an enabling environment for Internet Service Providers (ISPs) to extend their services to these towns and subsequently increase Internet connectivity in the rural areas.

\section{Rural Electrification}

The Government should accelerate the implementation of the Rural Electricity Projects (REP) in the country. This can be done by strengthening the management and resource base of these projects in order to improve the performance and impact of rural electrification. To further encourage diffusion of ICT services among the population, the Government should seek alternative sources of energy such as installing stand-alone generators in areas away from the grid network to 
serve communities not connected to grid system. The Government should also offer tariff incentives to users of alternative energy sources. This would pave the way for application and use of ICTs in disseminating agricultural information for rural development.

\section{-National ICT Policy}

A draft national ICT policy is under discussion and soon it will be presented as a bill and later enacted through an Act of Parliament. The policy is expected to play a significant role as part of an overall national strategy for development. The policy should be an enabler of social-economic development and should provide guidelines in the adoption of holistic, cross-sector strategies aimed at harnessing the potential of ICT to accelerate a wider development process in the country. The policy should focus on the following interrelated areas for strategic intervention, infrastructure, human capacity - building a critical mass of knowledge workers, increasing technical skills among users and strengthening local entrepreneurial and managerial capabilities. It should also focus on universal access to ICT tools and services and provide demand-driven information.

It is important to secure the participation and commitment of the key stakeholders such as NGO's, CBO's, private sector, and multinational institutions. The national ICT policy would therefore guide diffusion of ICTs in all sectors of economy including the agricultural sector.

\section{Institutional ICT policy}

The institutions (KARI and MOARD) set up an ICT Advisory Board to revise their ICT policies in line with the strategic framework for national ICT policy. ICTs should form the core institutional strategy for disseminating agricultural technologies and networking with collaborators.

\section{ICT Funding}

Due to inadequate funds the Ministry of Agriculture and Rural Development and the Kenya Agricultural Research Institute had to contend with several constraints including inadequate ICT training, over-reliance on donor projects, inadequate ICT tools and services among others. In this regard, it is recommended that the Ministry of Agriculture and KARI explore alternative sources of funding. A task force should be set up to come up with a proposal that could be tabled at the Ministerial (applies to ministry of agriculture) and Institute Board of Management (applies to KARI) respectively. The document should explore services that could be commercialized to generate income. The ICT department/section should form an integral part of these services and help in generating revenue through the provision of ICTs services. This could supplement the dwindling budget of ICTs in the respective institutions.

\section{-Employment of Information Technology (IT) Personnel}

It was found out that the application, use, and maintenance of ICTs is constrained by inadequate IT personnel as the few who had been employed were all stationed at the Ministry of Agriculture and KARI headquarters. In order to retain and attract ICT personnel, it is recommended that the Ministry of Agriculture and KARI find ways of motivating this cadre of professionals by giving them incentives emanating from the income generated funds. This is already happening in institutions of higher learning and they have managed to retain IT professionals. The two institutions should employ adequate IT professionals and deploy them to all the research centres and district agricultural offices. With adequate IT staff it would be possible to generate income from commercialized ICTs services. The technical staff would maintain the ICT tools and services and also provide information literacy programmes to all staff.

\section{-Information Literacy Programmes}

The Ministry of Agriculture and KARI should have an integrated information literacy programme with the objective of developing an ICT literate staff through retraining and skills building progression. The programme should be conducted jointly by the library staff and IT personnel. It should be offered on a continuous basis and emphasis should be placed on hands-on experience to enable staff gain skills and confidence to use a variety of ICTs. The literacy programme should be offered progressively starting from the very basic skills of using computers to advanced skills of using the Internet search engines. This would allow staff to put the gained skills into practice before advancing further. The literacy programmes should cover all aspects of ICT use. Staff should also be trained on repackaging of agricultural information using media such as radio and television. It is expected that the skills gained would help in creating confidence among agricultural researchers and extension workers and enable them to use a variety of ICTs in disseminating agricultural information.

To ensure development of a sustainable human capacity that effectively addresses the current digital divide both within the country and internationally, there is need to mainstream information and communication technology education and training in the national curricula and training programmes. 


\section{-Networking and collaboration}

Networking within the institutions should be improved so that email and Internet facilities are available to all researchers and extension workers. It is suggested that the Virtual Extension, Research and Communication Network (VERCON), an Internet based ICT system developed by FAO to link agricultural researchers and extension workers could be adopted by KARI and MoARD. This could facilitate the sharing and exchange of electronic agricultural knowledge. With the availability and access of Internet and email services, researchers and extension workers would be able to communicate more frequently and share information locally and at international level.

There is need for increased collaborative linkages between KARI and the Ministry of Agriculture and also with all actors involved in agricultural research and extension. The actors include NGO's, CBO's, Agro-chemical industries, stockists and traders, farmers association, universities, mass media and donor community among others. Studies (Ndungu, Nkonge and Rees 2000:8) have shown that when actors do not collaborate they tend to provide information to farmers independent from one another. Such information may be overwhelmingly huge for the farmers and may end up confusing rather than helping them. Collaborative linkages would, therefore, ensure that farming community gets relevant and timely information in appropriate formats. In other words, all actors would participate in the process of catalyzing the adaptation and adoption of agricultural technologies and knowledge among the farming community. Such collaboration may also enhance development of appropriate ICT models for research and extension. The end result would be an improvement in agricultural activities.

It is further recommended that the Kenya Agricultural Research Database at KARI and local databases at the Ministry of Agriculture be merged to form one database which can be posted on the Internet so that it is available internationally and also locally to many interested parties. The two institutions can also develop an intranet to allow their databases to be available for sharing among their staff and also other interested researchers. Individual researchers and extension workers are also encouraged to join Internet discussions groups and post their research output on the Internet. This will allow wider dissemination of research findings.

\section{- Monitoring and Evaluation of ICTs projects}

The problem of sustainability of many ICT projects at KARI and the Ministry of Agriculture was attributed to poor planning and management. It is recommended, therefore, that KARI and the Ministry of Agriculture develop a monitoring and evaluation system for ICT projects funded by institutions and donor community. Such a system would help in evaluating the viability and sustainability of all ICT projects. The criteria to form the basis for developing such a system could include relevance, sustainability, performance, effectiveness, and efficiency.

\section{-Establishment of the Ministry of Information and Communication Technology}

The Kenya Government establishes a Ministry of Information and Communication Technology to coordinate the development of the ICT sector in the country. This recommendation has already been accepted by the Government and Ministry of Information and Communication was established in February 2005. In the past, coordination of ICTs was fragmented under the docket of multiplicity of ministries that include the Ministry of Tourism and Information, Ministry of Transport and Communication, Ministry of Panning and National Development, Ministry of Education, Science and Technology, and the Ministry of Finance. This made coordination of ICT sector to be poor and lacking in focus as many actors were implementing different things which were not harmonized. Now that a ministry has been set up to coordinate the ICT activities it would be easy to implement the new national ICT policy once it is enacted. The role of the ministry is to harmonize all the ICT activities in the country and coordinate development of the ICT sector.

\section{References}

Ajit, M. (2003). Information and communication technology use in agricultural extension in India. Paper presented at the CTA ICT Observatory 2003: ICTs-transforming agricultural extension. Wageningen 23-25 September 2003.

Calvo, A. and Rahrig, K. (1999). Diffusions of Innovations. University of South Florida: community and Family Health. [on-line] available: http://hsc.usf.edu/ kmbrown/Diffusion_of_Innovations_Overview.htm [accessed 20/6/02]. research: electronic networking applications and policy, 6(1996) 4I-63.

Heeks, R. (1999). Information and Communication Technologies, poverty and development. Development informatics working paper no. 5. Institute for development policy management, University of Manchester [online], Available: http:// idpm.man.ac.uk/idpm/diwpf5.htm [accessed 9/4/02].

Ikoja-Odongo, J.R (2002). The study of information needs and uses of the informal sector of Uganda. Ph.D. thesis (unpublished), University of Zululand.

Kaniki, A.M. (1995). Agricultural user populations and critical tasks in Africa. In: L.O. Aina, A.M. Kaniki and J.B. Ojiambo Eds. Agricultural information in Africa. Ibadan, Third world information services.

Kenya Agricultural Research Institute (KARI) (2000). A strategic plan for the period 2000-20I0. KARI: Nairobi.

Kenya Agricultural Research Institute (KARI) (2003). KARI at a glance. KARI: Nairobi. 
Kenya Agricultural research Institute (2002). Third medium term plan July 2003 to June 2008. KARI: Nairobi.

Kenya, Republic of, Ministry of Agriculture and Rural Development (200I). National Agricultural Extension Policy (NAEP). Nairobi: MoARD.

Kenya, Republic (2002). National Development Plan 2002-2008. Nairobi: Govt. Press.

Kenya, Republic of (2000). Economic survey. Nairobi: Nairobi: Central Bureau of Statistics.

Kenya, Republic of, Ministry of Agriculture and Rural Development (1997). Assessment of information needs and of options of management: second post study workshop report. Nairobi: MoARD.

Kiome, R.M. (2002). KARI annual report. [on-line], available: http://www.kari.org/ introduction.htm [accessed on 12/4/02.

Kiplang'at, J.K.(2004) Diffusion of Information and Communication Technologies in Communication of Agricultural Information among Agricultural Researchers and Extension Workers in Kenya, University of Zululand, KwaDlangezwa (unpublished PhD thesis)

Larsen, T.J. (1998). Information systems innovation: A framework for research and practice: In Larsen, T.J. and McGuire, E. (Eds). Information systems innovation and diffusion: issues and directions. Hersey, PA: IDEA Group Publishing, 4I I-434.

Larsen, T.J. (1997). Diffusion theory as basis for understanding information technology related change: true or false? [on-line]

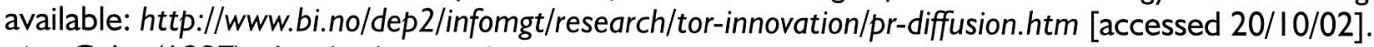

Lewis, G.A. (1997). Leadership products as innovations in context of Rogers' Diffusion Theory. Ph.D. dissertation. Virginia Polytechnic Institute and State University.[on-line] available: http://scholar.lib.vt.edu/theses/available/edt-/1997-/767/ unrestricted/EDT.PDF [accessed I8/6/02].

Minishi-Majanja M.K. and Kiplang'at, J. (2004). The diffusion of innovations theory as theoretical framework in library and information science research. In Bothma, T.J.D and Kaniki, A.(eds), Proceedings of $3^{\text {rd }}$ biennial DISSAnet Conference, Pretoria, 28-29 Oct 2004. :325-34I.

Minishi-Majanja M.K. and Kiplang'at, J. (2005). The diffusion of innovations theory as theoretical framework in library and information science research. South African Journal of Libraries and Information Science, Vol.7I(3)

Mugenda, O.L and Mugenda, A.G. (1999). Research methods: quantitative and qualitative approaches. Nairobi: African Centre for Technology Studies (ACTS) Press.

Ndungu, F.W. Nkonge, C. and Rees, D.J. (2000) Agricultural knowledge and information systems (AKIS) paradigm: It's potential in disseminating soil management technologies. Paper presented at soil and legume research network conference. Mombasa $26^{\text {th }}-30^{\text {th }}$ June 2000.

Ojiambo, J.B. (1989). Communication of agricultural information between research scientists, extension personnel and farmers in Kenya. Ph.D. Thesis (unpublished). University of Pittsburgh.

Ojiambo, J.B. (1995). Agricultural Information Systems in Kenya. In: L.O. Aina, A.M. Kaniki and J.B. Ojiambo Eds. Agricultural information in Africa. Ibadan, Third world information services.

Owino, F. (1999). The role of international organisation and non-governmental organisations in information support for agricultural policy formulation in Kenya. Wageningen, Netherlands: CTA.

Rogers, E.M. (1995). Diffusion of Innovations, $4^{\text {th }}$ Ed. New York: Free Press.

Rogers, E.M. and Scott, K.L. (1999). The Diffusion of Innovations model and outreach from the national network of libraries of medicine to Native American communities. [online] available: $h t t p: / / n n l m . g o v / p n r / e v a l /$ rogers.html [accessed on 20/6/02].

Sunding, D. and Zilberman, D. (2000). The agricultural innovation processes: research and technology adoption in a changing agricultural sector.[on-line] available: $h t t p: / / a r e . b e r k e l e y . e d u / z i l b e r / i n n o v a t i o n c h p t r . p d f$ [accessed 22/6/02].

Surry, D.W. (1997). Diffusion theory and instructional technology. University of Southern Mississippi. [on-line] available: http:// www.gsu.edu/ wwwitr/docs/diffusion/ [accessed 20/10/02].

The Technical Centre for Agricultural and Rural Cooperation (CTA) (2003). ICT Observatory 2003: ICTs- transforming agricultural extension? Background information. [on-line] available: http://www.cta.int/observatory2003/documents.htm [accessed on 26/II/ 03].

\section{Notes}

The original version of this Paper was Presented at the IAALD XITH World Conference/USAIN Biennial Conference: Globalisation of Information: Agricultural at Crossroads. Lexington, Kentucky, USA, May 14-19, 2005. 